Canadian

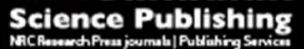

Canadian Journal of Civil Engineering Revue canadienne de génie civil

\title{
Suspended Solids in an End Pit Lake: Potential Mixing Mechanisms
}

\begin{tabular}{|r|l|}
\hline Journal: & Canadian Journal of Civil Engineering \\
\hline Manuscript ID & cjce-2015-0381.R1 \\
\hline Manuscript Type: & Article \\
\hline Date Submitted by the Author: & $12-$ Nov-2015 \\
\hline Complete List of Authors: & $\begin{array}{l}\text { Lawrence, Gregory; University of British Columbia, Department of Civil } \\
\text { Engineering } \\
\text { Tedford, Edmund; U.B.C., Civil Engineering } \\
\text { Pieters, Roger; University of British Columbia, Earth and Ocean Sciences }\end{array}$ \\
\hline Keyword: & end pit lakes, oil sands, wind waves, threshold velocity \\
\hline
\end{tabular}




\section{Suspended Solids in an End Pit Lake: Potential Mixing Mechanisms}

Gregory A. Lawrence ${ }^{1}$, Edmund W. Tedford ${ }^{1}$ and Roger Pieters ${ }^{2}$

1.Department of Civil Engineering, University of British Columbia, Vancouver, BC, Canada

2.Department of Earth Ocean and Atmospheric Sciences, University of British Columbia, Vancouver, BC, Canada

Corresponding Author:

Greg Lawrence

Department of Civil Engineering

\#2030 - 6250 Applied Science Lane

Vancouver, BC V6T 1 Z4

Tel: 604-822-5371

Email: lawrence@civil.ubc.ca

Word Count: 4,740 


\section{ABSTRACT:}

The production of crude oil from the Canadian oil sands has generated tailings ponds that contain oil sands process-affected water and oil sands fluid fine tailings (FFT). One remediation strategy is to backfill a mined out pit with FFT and cap this with a mix of oil sands process-affected water and fresh water to form a lake, called an end pit lake. Here we discuss various mechanisms governing the vertical mixing of suspended solids in an end pit lake. Depending on the depth of the water cap, wind waves can cause mixing between the water cap and the FFT. Other potential mixing mechanisms include: convection due to salt-water exclusion during ice formation, penetrative convection due to surface cooling, gas emission from the FFT, and internal wave activity. Data collected at Syncrude Canada Limited's Base Mine Lake in 2013/14 are used to demonstrate the effects of some of these processes.

Keywords: end pit lakes; oil sands; fluid fine tailings; wind waves; threshold velocity; turbidity; gas emission 


\section{INTRODUCTION}

The extraction of crude oil from the Canadian oil sands has produced large quantities of fluid fine tailings (FFT) and oil sands process-affected water. One remediation strategy is to create an "end pit lake" by backfilling a mine pit with FFT and capping it with a mix of process-affected water and fresh water, as idealised in Fig. 1a. Syncrude Canada Limited's Base Mine Lake (BML), located about 40 km north of Fort McMurray, Alberta, is the oil sands industry's first demonstration end pit-lake. The filling of BML was completed in October 2013, at which time it had a surface area of $7.9 \mathrm{~km}^{2}$ and an approximately $8 \mathrm{~m}$ deep water-cap, covering a layer of FFT up to $50 \mathrm{~m}$ deep with a volume of $180 \times 10^{6} \mathrm{~m}^{3}$. Between October 2013 and May 2015 the average depth of the water cap increased by $1 \mathrm{~m}$ due to settling of the FFT. Significant efforts are being made to monitor and understand the evolution of BML in response to this settling and to various other processes. Of particular interest are the turbidity, and the related concentration of total suspended solids (TSS), in the water-cap, which affect both the future ecology of the lake and the management of any discharge from it.

Studies of the turbidity of a water-cap overlying FFT began over twenty years ago, when the average turbidity in the water cap of Syncrude's Mildred Lake Settling Basin (MLSB) was increasing in response to the addition of FFT and a corresponding reduction in the depth of the water cap. These studies provide a foundation for understanding turbidity in nearby BML. Lawrence et al. (1991) determined that the oscillating bottom currents beneath surface wind waves were the most likely cause of erosion of FFT in MLSB (Fig. 
2a). They calculated the wind speed needed to generate wind-waves with bottom currents sufficiently strong to erode the FFT for a given depth of water cap.

Ward et al. (1994) noted that winds strong enough to erode the FFT in MLSB were infrequent, and for the most part changes in turbidity were due to the vertical movement of particles already in the water cap. During calm periods particles settled to form an intermediate, turbid layer at the base of the water-cap (Fig. 1b) analogous to the fluid mud often found in estuaries (McNally et al. 2007) and far less dense and far more mobile than the gel-like FFT. This material was subsequently re-suspended during storms that were not strong enough to erode the underlying FFT.

While MLSB and BML are in close proximity to each other, have similar fetches, and are filled with basically the same material, they will respond differently to wind forcing. The depth of the water cap in MLSB has been less than 6 m since 1990; whereas, the water cap in BML is an average of about $9 \mathrm{~m}$ and increasing. Given that the oscillating currents beneath surface wind waves decrease exponentially with depth, these currents are far less likely to disturb the FFT in BML than in MLSB.

Another significant difference between MLSB and BML is that while BML is designed as a final reclamation landform, with no solids being added or removed (except those suspended in water pumped in or out) and therefore subject to relatively little disturbance; MLSB is an integral component of the mining/extraction/tailings operation with variable quantities of solids continuously being discharged into it and a continuous removal of water from the water cap for use in the extraction process, and therefore is 
subject to considerable on-going disturbance. Thus there may be processes that affect the turbidity of BML that were not apparent in the previous studies of MLSB.

The goal of the present study is to provide a preliminary assessment of the range of processes that may affect turbidity in BML. In Section 2 we summarize the results of studies of wind-driven mixing in MLSB, and their applicability to BML. In Section 3 we discuss other potential FFT driven transport mechanisms in BML. We then examine turbidity and other field data from BML in 2013 and 2014, and provide explanations for the observed behaviour. We conclude with a summary of the potential mechanisms governing turbidity in the water cap of BML.

\section{WIND-DRIVEN MIXING}

As the depth of the water cap in MLSB decreased in the late 1980's, increasing TSS was of concern given that recycled water from MLSB was a major source of water for Syncrude's oil sands extraction process (MacKinnon 1989). To determine the depth of water cap needed to prevent the wind-wave driven transport of solids from the FFT into the water cap, Al McLaren conducted experiments at Western Canada Hydraulics Laboratories. Samples of FFT from just below the mudline in MLSB were placed in the bed of a flume and subjected to progressive surface waves (Fig. 2a). The threshold velocity, $U_{t}$, defined as the magnitude of the oscillating current at the mudline necessary to initiate erosion of the FFT, was found to be approximately $4 \mathrm{~cm} / \mathrm{s}^{1}$. The details of the erosion process are not known; however, the research of Jamali et al. 2003 and Jamali

\footnotetext{
${ }^{1}$ Deeper samples of FFT, representative of material subsequently transferred to BML, were found to have a threshold velocity of approximately $5 \mathrm{~cm} / \mathrm{s}$.
} 
\& Lawrence, 2006 suggests that the breaking of resonant waves at the mudline, may release FFT into the water cap.

Based on linear wave theory Lawrence et al. (1991) estimated the design depth of the water cap to avoid erosion of the FFT by progressive, fetch-limited, surface waves:

[1] $d_{\text {des }}=0.00187\left(\frac{U^{2} F^{2}}{g}\right)^{1 / 3} \ln \left[0.037 \frac{R\left(g F U^{4}\right)^{1 / 3}}{U_{t}}\right]$,

where $U$ is the design wind speed; $F$ is the wind fetch; $g$ is the gravitational acceleration; and $R$ is the ratio of the design wave height to the significant wave height (equal to the average height of the highest one-third of the waves). For these waves to be fetch-limited the design wind speed needs to be sustained for a minimum duration:

[2] $\quad t_{d}=68.8\left(\frac{F^{2}}{g U}\right)^{1 / 3}$.

Using values appropriate for a 1 in 10 year windstorm at MLSB $\left(U=17 \mathrm{~m} / \mathrm{s}\left(t_{d}=1 \mathrm{hr}\right)\right.$, $F=5 \mathrm{~km}, R=1$ and $U_{t}=4 \mathrm{~cm} / \mathrm{s}$ ) Lawrence et al. (1991) calculated a design depth of 6 m. While too much reliance shouldn't be placed on this result given the assumptions made in obtaining it, the TSS concentrations in MLSB were observed to increase substantially when the depth of the water cap decreased to less than $6 \mathrm{~m}$ (M. MacKinnon, pers. comm.). Note that while the threshold velocity is difficult to determine accurately, the design depth is relatively insensitive to it. Decreasing the threshold velocity from 4 to $2 \mathrm{~cm} / \mathrm{s}$ only increases the design depth by $19 \%$. 


\subsection{Field study at Mildred Lake settling basin}

A field study was conducted at MLSB in the late summer and early autumn of 1991 (Ward et al. 1994). During this period the water cap was $5.5 \mathrm{~m}$ deep, which from Eq. [1] corresponds to the design depth for a wind speed of $15 \mathrm{~m} / \mathrm{s}$, which from [2] would need to be sustained for $1.1 \mathrm{hr}$. A peak hourly wind speed of $11.7 \mathrm{~m} / \mathrm{s}$ was measured on September $24^{\text {th }}$. Therefore, it is unlikely that wind-wave induced erosion of the FFT occurred. On the other hand a dramatic increase in turbidity was observed during the peak winds on September $24^{\text {th }}$ (Fig. 3). The rate at which energy is imparted to the water column is proportional to the wind speed cubed (Fischer et al. 1979), which is seen to correlate closely to the increase in TSS in the water cap. The early morning of September $24^{\text {th }}$ was calm and the TSS dropped slightly, as the wind speed picked up the TSS started to increase gradually, then at about 9 am the wind speed increased rapidly - as did the TSS. The TSS continued to rise until about $6 \mathrm{pm}$, after which time the wind died down and the TSS dropped. These observations support the hypothesis that TSS variations in the water cap may often be due to re-suspension of fluid mud from an intermediate, turbid layer at the base of the water cap rather than erosion of the underlying FFT.

\subsection{Application to Base Mine Lake}

Using parameters appropriate to BML $\left(U=17 \mathrm{~m} / \mathrm{s}, F=4 \mathrm{~km}, R=1\right.$, and $\left.\mathrm{U}_{\mathrm{t}}=5 \mathrm{~cm} / \mathrm{s}\right) \mathrm{Eq}$. (1) gives a design depth, $\mathrm{d}_{\mathrm{des}} \approx 5 \mathrm{~m}$. This depth was used as a minimum depth in the initial planning stages of BML (G. Halferdahl, pers. comm.). However, it is important to 
note that when the filling of BML was complete (October 2013) the average depth of the water-cap was $8 \mathrm{~m}$, and by May 2015 it had increased to approximately $9 \mathrm{~m}$ due to settling of the FFT.

The fact that the water cap is deeper than the design depth is important, since the orbital velocity beneath waves decreases exponentially with depth, $d$, according to:

[3] $\quad \mathrm{U}_{\mathrm{orb}}=\frac{2 \pi \mathrm{H}}{T \exp \left(\frac{2 \pi \mathrm{d}}{\mathrm{L}}\right)}$

Lawrence et al. (1991). For BML the design wave height, $H=0.0016 \sqrt{F U^{2} / g}=0.55 \mathrm{~m}$; the wave period, $T=0.2714 \sqrt[3]{F U / g^{2}}=2.4 \mathrm{~s}$; and the wavelength, $L=g T^{2} / 2 \pi=9 \mathrm{~m}$. The orbital velocity matches the threshold velocity of $5 \mathrm{~cm} / \mathrm{s}$ at a depth of approximately $5 \mathrm{~m}$, but when the depth is increased to $8 \mathrm{~m}$ the orbital velocity is just $0.6 \mathrm{~cm} / \mathrm{s}$ (Fig. 2b). A wind speed of $30 \mathrm{~m} / \mathrm{s}$ would be required to generate an orbital velocity of $5 \mathrm{~cm} / \mathrm{s}$ at the bottom of an $8 \mathrm{~m}$ water cap, and this velocity would have to be sustained for about an hour for the waves to grow to their maximum height. A review of historical wind data, reveals that such winds are highly improbable at BML.

\subsection{Other wind-driven mechanisms}

There are numerous other potentially important mechanisms driven by the wind, including: turbulence beneath breaking waves, wind-driven basin-scale circulation, Langmuir circulation, wave breaking and wave reflection at the shoreline, and turbidity currents resulting from shoreline erosion. Lawrence et al. (1991) eliminated most of 
these mechanisms as potential sources of FFT erosion in MLSB, and the others were tacitly assumed to be less important than the orbital motions beneath wind waves. On the other hand, these mechanisms could cause re-suspension from any intermediate layer of fluid mud that forms at the base of the water cap. In the case of BML, which is deep enough to thermally stratify during summer, currents driven by basin scale internal seiches, and turbulence from the breaking of smaller scale internal waves are additional potential sources of mixing. It remains to be seen what the effects of the combination of all these wind-driven mechanisms are on TSS concentrations in BML. It should also be noted that the potential reduction in the magnitude of these effects, due to a hydrocarbon film on the surface of BML, has yet to be investigated.

\section{POTENTIAL FFT-DRIVEN TRANSPORT MECHANISMS IN BASE MINE LAKE}

While the FFT is resistant to disturbance because of its high density and viscosity, it has properties that may result in the transport of solids into the water cap, namely: it is releasing gasses, it is warm, and it is settling.

Echo soundings were collected under the ice at BML during the winter of 2014 . At 23 out of 24 sites, gas bubbles were observed to be rising through the water column (Fig. 4). These bubbles are presumably transporting some solids from the FFT into the water cap, and they may also be generating circulation and mixing within the water cap.

For a large portion of the year the water cap is cooler than the FFT, and there is the potential for thermally driven convection. However, it should be noted that there are many highly stable water bodies where other stratifying agents suppress thermal 
instabilities. A remarkable example is Hot Lake in Central Washington, USA, which is relatively fresh down to a depth of $1 \mathrm{~m}$, but has a total dissolved solids concentration of about $200 \mathrm{~g} / \mathrm{L}$ below $1 \mathrm{~m}$. Temperatures in the saline lower layer of this lake exceed 50 ${ }^{\circ} \mathrm{C}$ in summer; even when the surface of this lake is frozen the temperature at a depth of $2 \mathrm{~m}$ approaches $30^{\circ} \mathrm{C}$ (Anderson, 1958). Thus, while the base of the water cap of BML is thermally unstable for much of the year, it is likely that the stratification provided by both suspended and dissolved solids will maintain stability. Nevertheless, the roles of thermal instability, the double diffusion of heat and salt, and the stability provided by suspended and dissolved solids warrant investigation.

Between October 2013 and May 2015 approximately $6 \times 10^{6} \mathrm{~m}^{3}$ of pore water was expressed from the settling FFT into the base of the water cap, increasing the volume of the water cap by approximately $10 \%$. When storms mix this expressed pore-water into the water cap, the TSS of the water cap will change. Unfortunately, to date we have no measurements of the TSS of the expressed pore water, so we cannot calculate the potential impact of this pore water on the TSS of the water cap.

\section{OBSERVATIONS OF MIXING IN THE WATER CAP OF BASE MINE LAKE}

Here we use selected field data collected between October 2013 and November 2014 to illustrate some of the mixing mechanisms within the water cap of Base Mine Lake. In early November 2013 the water cap was undergoing fall turnover and cooling by approximately $0.5^{\circ} \mathrm{C} /$ day (Fig. 5b). The surface of the lake froze on 10 November 2013 
$(\text { Day }-51)^{2}$ and remained frozen until 1 May 2014 (Day 121). The lake then remained ice-free until 7 November 2014 (311), and exhibited thermal stratification from earlyJune until mid-September (Fig. 6a).

Just before ice-on in November 2013 the water cap had a temperature of $1.4{ }^{\circ} \mathrm{C}$, a specific conductivity of $3.2 \mathrm{mS} / \mathrm{cm}$ (corresponding to a salinity of approximately $2 \mathrm{ppt}$ ), and a dissolved oxygen concentration (DO) equal to $50 \%$ of saturation (Fig. 5). Notable changes were observed in the water cap during ice-cover. The conductivity increased from $3.2 \mathrm{mS} / \mathrm{cm}$ to $3.5 \mathrm{mS} / \mathrm{cm}$ due to salt exclusion from the ice (Fig. $5 \mathrm{c}$ ); assuming complete exclusion of salt from the ice, these values yield a predicted ice thickness of $0.7 \mathrm{~m}$, which is consistent with the $0.6 \mathrm{~m}$ average of ice thicknesses measured at several locations on 9 March 2014 (99). Dissolved oxygen was consumed at a relatively constant rate until it reached zero about 10 days before ice-off (Fig. 5d). The lake stratified thermally (Fig. 5b) with the magnitude of the temperature difference between $\mathrm{d}=3 \mathrm{~m}$ and $\mathrm{d}=4 \mathrm{~m}$ fluctuating rapidly presumably due, at least in part, to the downward passage of saline plumes (Fig. 5e).

The above observations are broadly consistent with the field observations of Pieters and Lawrence (2009) and the laboratory experiments of Bluteau (2006). One exception is that in the laboratory experiments temperature and conductivity fluctuations were not observed during ice-thaw; whereas, they persist in BML. These fluctuations during icethaw, when there are no descending saline plumes, may be due to a variety of

\footnotetext{
${ }^{2}$ The Day of Year 2014 is indicated in brackets after each calendar date.
} 
mechanisms including solar heating through the ice, rotating gyres (Forrest et al. 2013), differential heating and cooling, and thermal convection driven by the warm FFT.

On 13 \& 14 February 2014 (44 \& 45) under ice measurements of TSS were made throughout the water column at platforms located in the centre and the northeast (NE) and southwest (SW) quadrants of the lake. The average TSS concentrations were 28, $30,44,43$ and $135 \mathrm{mg} / \mathrm{L}$ at $\mathrm{d}=0.2,2,4,6$ and $8 \mathrm{~m}$, respectively. The fact that these values are higher than those recorded during the summer (Fig. 6b) has stimulated plans for intensified under-ice data collection to investigate potential vertical mixing mechanisms.

After ice-off the water cap began to warm, and by mid-June was strongly temperature stratified; this stratification persisted until the start of fall turnover in early September (Fig. 6a \& c). Broadly speaking, during summer stratification mixing due to surface wind waves and penetrative convection was isolated to the upper portion (epilimnion) of the lake, and surface TSS progressively decreased due to particle settling (Fig. 6b). When the lake turned over, the solids that had settled during summer were re-suspended, probably due to penetrative convention and wind action, and the turbidity steadily rose.

Temperature and turbidity profiles were measured using a Seabird SBE19plus profiler with a Seapoint turbidity sensor; the profiler was allowed to descend until the weight of the instrument was insufficient for it to penetrate further into the FFT. Five profiles were taken at the NE platform in 2014. Toward the bottom of each profile, when the turbidity sensor encountered the intermediate layer, it ceased to provide meaningful readings above a turbidity of about 500 NTU (only the meaningful readings are shown in Fig. 7c). 
Measurements with a sensor with a higher maximum turbidity threshold are needed to accurately characterise the intermediate layer. However, the temperature sensor continued to provide reliable measurements throughout the profiles, with the profiler descending between $0.5 \mathrm{~m}$ and $1.5 \mathrm{~m}$ below the depth of the last meaningful turbidity reading (Fig. 6d). We can interpret the depth of the last meaningful turbidity reading as the profiler entering the intermediate fluid mud layer; the profiles suggest that the thickness of the intermediate layer varies through time.

It should also be noted that the thickness of the intermediate layer is likely to vary in space due to variations in the elevation of the mudline. Sonar mudline contour maps indicate as much as $4 \mathrm{~m}$ difference between the highest and lowest elevations of the top of FFT around the lake; varying thicknesses and perhaps composition of FFT, and/or varying rates of dewatering and settling, are thought to contribute to these sub-basins. Experiments are underway to develop techniques to characterize the complex nature of the intermediate layer.

On 28 May 2014 (148), when the lake was weakly stratified, the turbidity increased gradually with depth, presumably due to particle settling, until it jumped abruptly at the top of the intermediate layer (Fig 6d). The highest surface TSS was measured in early June 2014 (Fig. 6b), after a strong windstorm on 30 May 2014 (150) that caused resuspension of fluid mud from the intermediate layer and mixed it throughout the water cap. By 7 July 2014 (188) the turbidity had decreased at all depths, but this decrease was highly non-uniform over the depth (Fig 6d). The lowest turbidity on 7 July was measured near the bottom, suggesting that while particle settling was important, other, 
as yet unknown, processes were also in play. Continued settling was apparent on 18 August 2014 (230) when the lowest turbidities of the year were measured. On 15 September 2014 (258) several days after turnover the turbidity had started to increase. By 14 October 2014 (287) the turbidity had further increased and was relatively uniform with depth above the intermediate layer.

While the data collected in 2014 provide useful insight into the vertical movement of solids in the water cap of Base Mine Lake, there are still important unanswered questions. In particular, it is still unclear whether or not the inventory of suspended solids is increasing, either due to erosion of the shoreline (from wind wave breaking and ice-scour), or due to vertical transport from the FFT. Year round data, especially just before ice-on and after ice-off, are needed to fill the gaps in our understanding.

\section{SUMMARY}

While the initial study of suspended solids concentrations in a water cap overlying FFT identified oscillating bottom currents beneath wind-waves as a potential source of erosion of the FFT (Lawrence et al. 1991), we have concluded that this is unlikely to be a major direct source of turbidity in Base Mine Lake. The water cap in Base Mine Lake is deep enough that these currents, which decrease exponentially with depth, are too weak to erode the FFT. We have briefly described a number of other processes that might affect the turbidity of BML, and have discussed some of them in the context of field data collected in 2013/14. 
Broadly speaking particle settling seems to be the dominant, but by no means the only, process affecting TSS in Base Mine Lake during summer. At a depth of $0.2 \mathrm{~m}$ the TSS dropped from about $100 \mathrm{mg} / \mathrm{L}$ at the beginning of June to about $1 \mathrm{mg} / \mathrm{L}$ in mid-August. The settled material appears to have formed an intermediate layer of elevated turbidity at the base of the water cap. During fall some of this material was re-suspended and mixed throughout the water cap, presumably by wind stirring and penetrative convection. By mid-Oct the TSS had increased to about $40 \mathrm{mg} / \mathrm{L}$. As yet we have insufficient data to make any conclusions about the distribution of suspended solids in the water cap during late fall, winter and early spring.

We have identified numerous processes that could conceivably affect suspended solids concentrations in Base Mine Lake, and in the absence of any additional information we cannot eliminate any of them as possibilities. There are undoubtedly more, including mixing due to earthquake induced motions (de la Fuente et al. 2010; Pieters and Lawrence, 2014). Our list of processes can be grouped according to those driven by the wind, those driven by the FFT, those occurring during ice-cover, and others.

\section{Wind-driven processes:}

1. Oscillating motions under wind-waves

2. Turbulent motions beneath breaking waves

3. Wind-driven circulation in the water cap

4. Langmuir circulation

5. Enhanced near-shore currents due to wave reflection and wave breaking

6. Turbidity currents resulting from shoreline erosion 
7. Internal seiche driven currents

8. Internal wave breaking

\section{FFT-driven processes}

9. Gas bubbles emerging from the FFT

10. Pore water expression from the FFT as it dewaters and settles under self weight

11. Thermal instability due to warm FFT below a cool water cap

12. Double diffusion

\section{Under-ice processes}

13. Convection due to salt-water exclusion during ice formation

14. Rotating gyres

15. Ice-scour

16. Solar induced under-ice convection

\section{Other processes}

17. Penetrative convection due to surface cooling

18. Differential heating and cooling

19. Inflows and outflows

20. Earthquake induced mixing

An extensive on-going monitoring program is being undertaken to gain a better understanding of the relative importance of each of these processes in BML. 


\section{ACKNOWLEDGEMENTS}

This work was supported by a collaborative research agreement between Syncrude Canada Limited and the University of British Columbia. The authors are grateful for information, advice and encouragement from Geoff Halferdahl. 


\section{REFERENCES}

Andersen, G.C. 1958. Some limnological features of a shallow saline meromictic lake. Limnology and Oceanography, 3(3): 259-270.

Bluteau, C. 2006. Mixing in brackish lakes due to surface ice. M.A.Sc. thesis, The University of British Columbia, Vancouver, B.C.

de la Fuente, F., Meruane, C., Contreras, M., Ulloa, H. and Nino, Y.. 2010. Strong vertical mixing of deep water of a stratified reservoir during the Maule earthquake, central Chile ( $M_{w}$ 8.8). Geophysical Research Letters, 37, L24608, doi:10.1029/2010GL045798.

Fischer, H.B., List, E.J.,. Koh, R.C.Y., Imberger, J. and Brooks, N.H.. 1979. Mixing in Inland and Coastal Waters. Academic Press, San Diego, California.

Forrest, A.L., Laval, B.E., Pieters, R. and Lim, D.S.S. 2013. A cyclonic gyre in an icecovered lake. Limnology and Oceanography, 58(1), 363-375.

doi:10.43/lo.2013.58.1.0363.

Jamali, M., Lawrence, G.A. and Seymour, B. 2003. A note on the resonant interaction between a surface wave and two interfacial waves. Journal of Fluid Mechanics, 491: 19. 
Jamali, M. and Lawrence, G.A. 2006. Viscous wave interaction due to motion of a surface wave over a sediment bed. Journal of Offshore Mechanics and Arctic Engineering, 128: 276-279.

Lawrence, G.A., Ward, P.R.B. and McKinnon, M.D. 1991. Wind-wave induced suspension of mine tailings in disposal ponds. Canadian Journal of Civil Engineering, 18(6): 1047-1053.

MacKinnon, M.D. 1989. Development of the tailings pond at Syncrude's oil sands plant: 1978 - 1987. AOSTRA Journal of Research, 5: 109-153.

McNally, W., Friedrichs, C., Hamilton, D., Hayter, E., Shrestha, P., Rodriguez, H., Sheremet, A., Teeter, A., and ASCE Task Committee on Management of Fluid Mud. 2007. Management of Fluid Mud in Estuaries, Bays, and Lakes. I: Present State of Understanding on Character and Behavior. J. Hydraul. Eng., 133(1), 9-22.

Pieters R. and Lawrence, G.A. 2009. Effect of salt exclusion from lake ice. Limnology \& Oceanography, 54, 401-412.

Pieters R. and Lawrence, G.A. 2014. Physical processes and meromixis in pit-lakes. Canadian Journal of Civil Engineering, 41(6): 569-578, http://dx.doi.org/10.1139/cjce2012-0132

Ward, P.R.B., Lawrence, G.A. and MacKinnon, M.D. 1994. Wind-driven re-suspension of sediment in a large tailings pond. Proceedings, International Symposium on Ecology and Engineering, Oct. 29 to Nov. 3, 1994. Jointly organized by Coastal and Offshore 
Engineering Institute, Universiti Teknologi Malaysia, and Centre for Water Research, University of Western Australia. VI: 37-57. 


\section{FIGURE CAPTIONS}

Figure 1. Idealisations of an end pit lake (a) with, and (b) without, an intermediate layer. The red lines give hypothetical percentages of solids by weight.

Figure 2. (a) Schematic of wind waves generating an oscillating current at the base of a water cap. (b) Predicted variation in orbital velocity in the water cap at Base Mine Lake (blue) as a function of depth, compared with the threshold velocity of $5 \mathrm{~cm} / \mathrm{s}$ (red).

Figure 3. Variation of the TSS concentration (red) measured in the water cap of MLSB at a depth of $1 \mathrm{~m}$, and the wind speed cubed (black) during 24 September 1991 . The dashed black line represents the wind speed $(15 \mathrm{~m} / \mathrm{s})$ needed to erode the FFT.

Figure 4. Echo sounding collected under the ice in BML on February $2^{\text {nd }} 2014$ using a Lowrance $200 \mathrm{kHz}$ sounder. The dark diagonal lines indicate gas bubbles rising at about $25 \mathrm{~cm} / \mathrm{s}$ from the FFT at a depth of about $8 \mathrm{~m}$. The horizontal lines, e.g. at a depth of $4.3 \mathrm{~m}$ indicated the presence of suspended material.

Figure 5. Times series from before ice-on, 10 November 2013 (-51), until after ice-off, 1 May 2014 (121), at the northeast platform in BML: (a) air temperature; (b) water temperature at $\mathrm{d}=3 \mathrm{~m}$ and $\mathrm{d}=4 \mathrm{~m}$; (c) specific conductivity (proportional to salinity); (b) dissolved oxygen (\% saturation); and (e) temperature difference between $\mathrm{d}=3 \mathrm{~m}$ and $d=4 \mathrm{~m}$. Water temperature, specific conductivity and dissolved oxygen were measured using a Hydrolab MS5.

Figure 6. Measurements taken during the 2014 open water season: (a) water temperature at 3, 5, 7 and 9 m depth, measured using RBR Solo T temperature loggers; 
profiles of (b) TSS measurements at the northeast, central and southeast platforms, from bottle samples collected at $0.2 \mathrm{~m}$ depth; and (c) and (d) temperature and turbidity profiles were taken at the northeast platform using a Seabird SBE19plus profiler CTD with a Seapoint turbidity sensor on 28 May (148), 7 July (188), 18 August (230), 15 September (258) and 14 October 2014 (287). The vertical lines in (a) and (b) correspond to the dates of the temperature and turbidity profiles. In BML the turbidity in NTU (Nephelometric Turbidity Units) is approximately three times the TSS in $\mathrm{mg} / \mathrm{L}$; i.e., water with a TSS of $100 \mathrm{mg} / \mathrm{L}$ has a turbidity of approximately $300 \mathrm{NTU}$. 
(a)
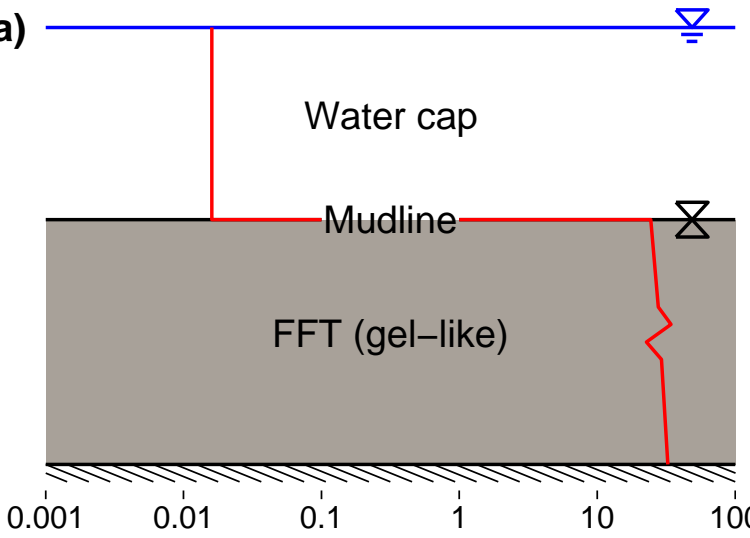

$1000.01 \quad 1000.1 \quad 10^{\prime} 01 \quad 10^{\prime} 10 \quad 11^{\prime} 00 \quad 265$ (b)

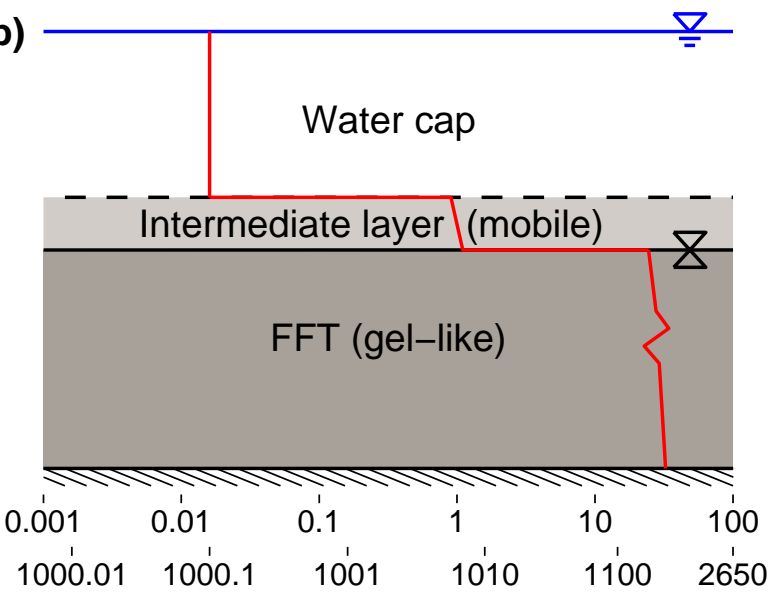


(a)

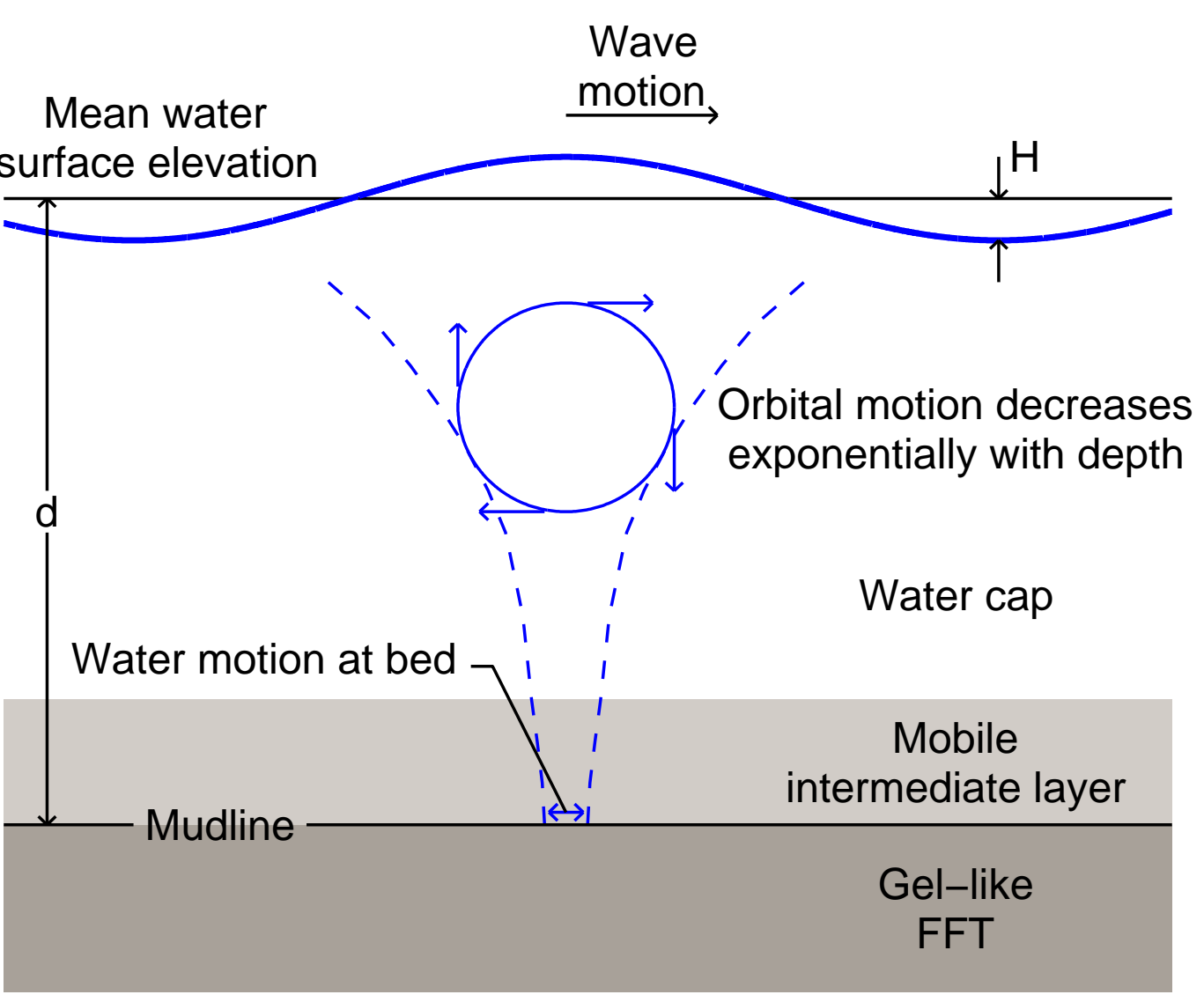

(b)

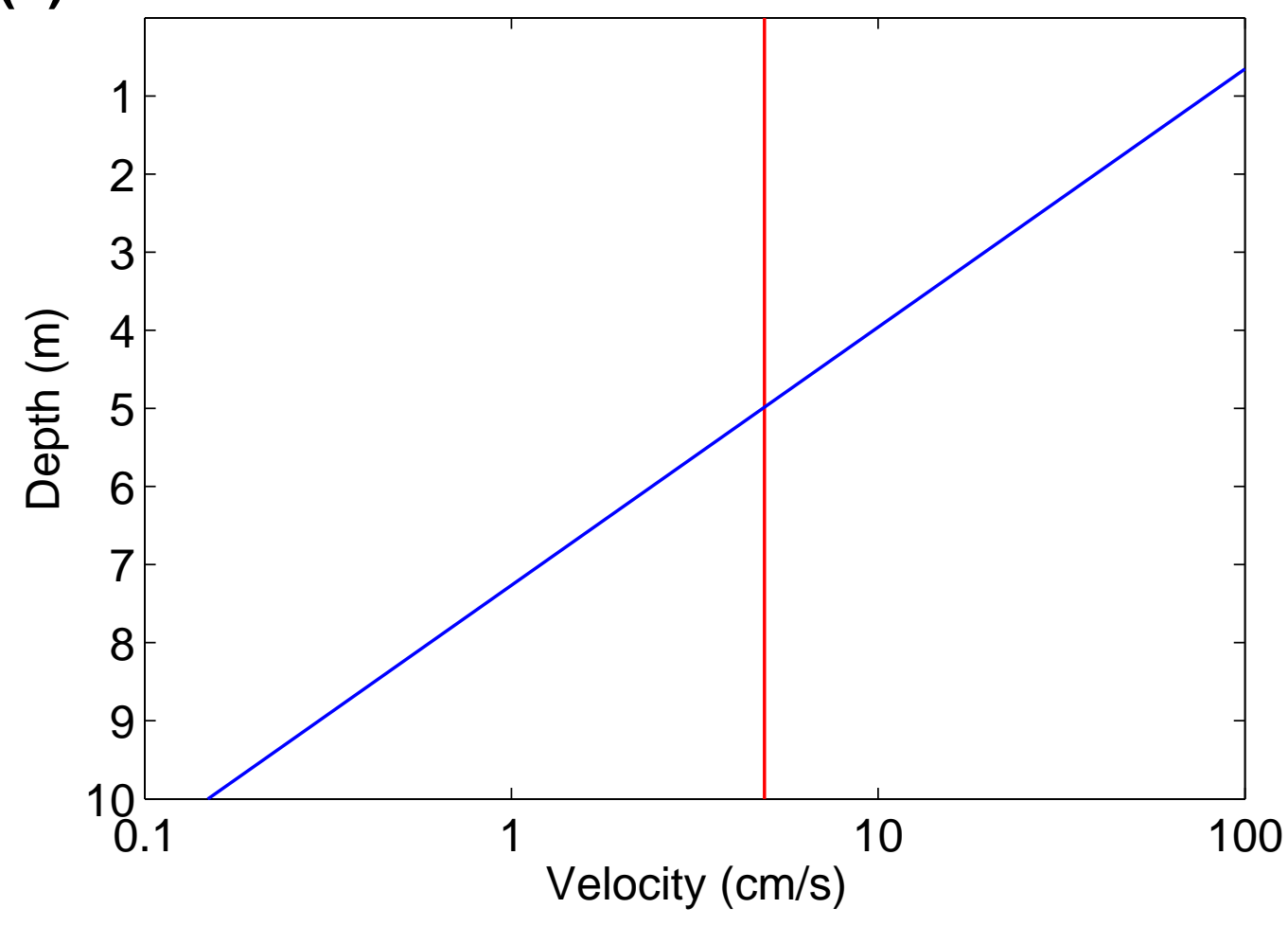




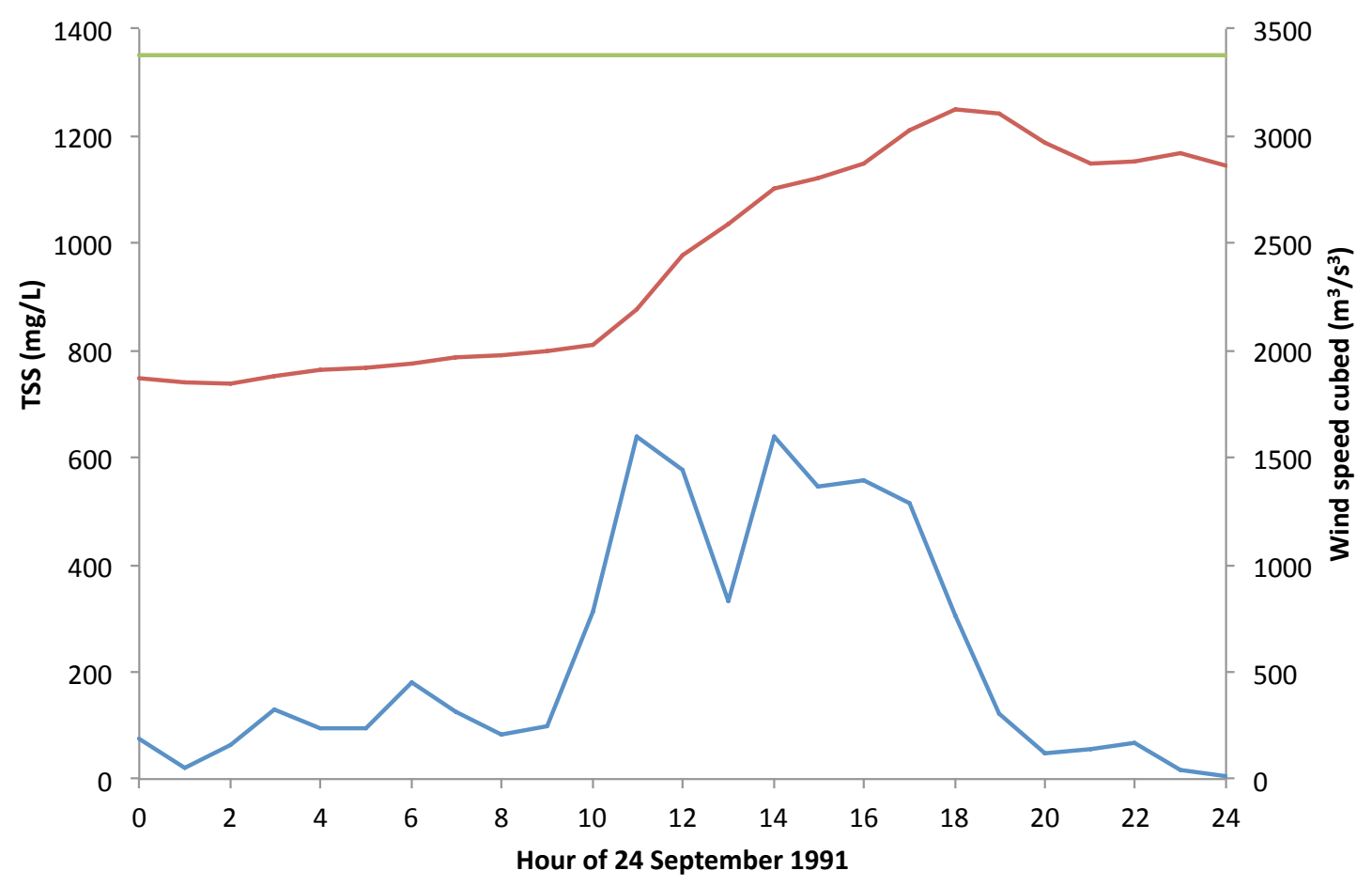

https://mc06.manuscriptcentral.com/cjce-pubs 


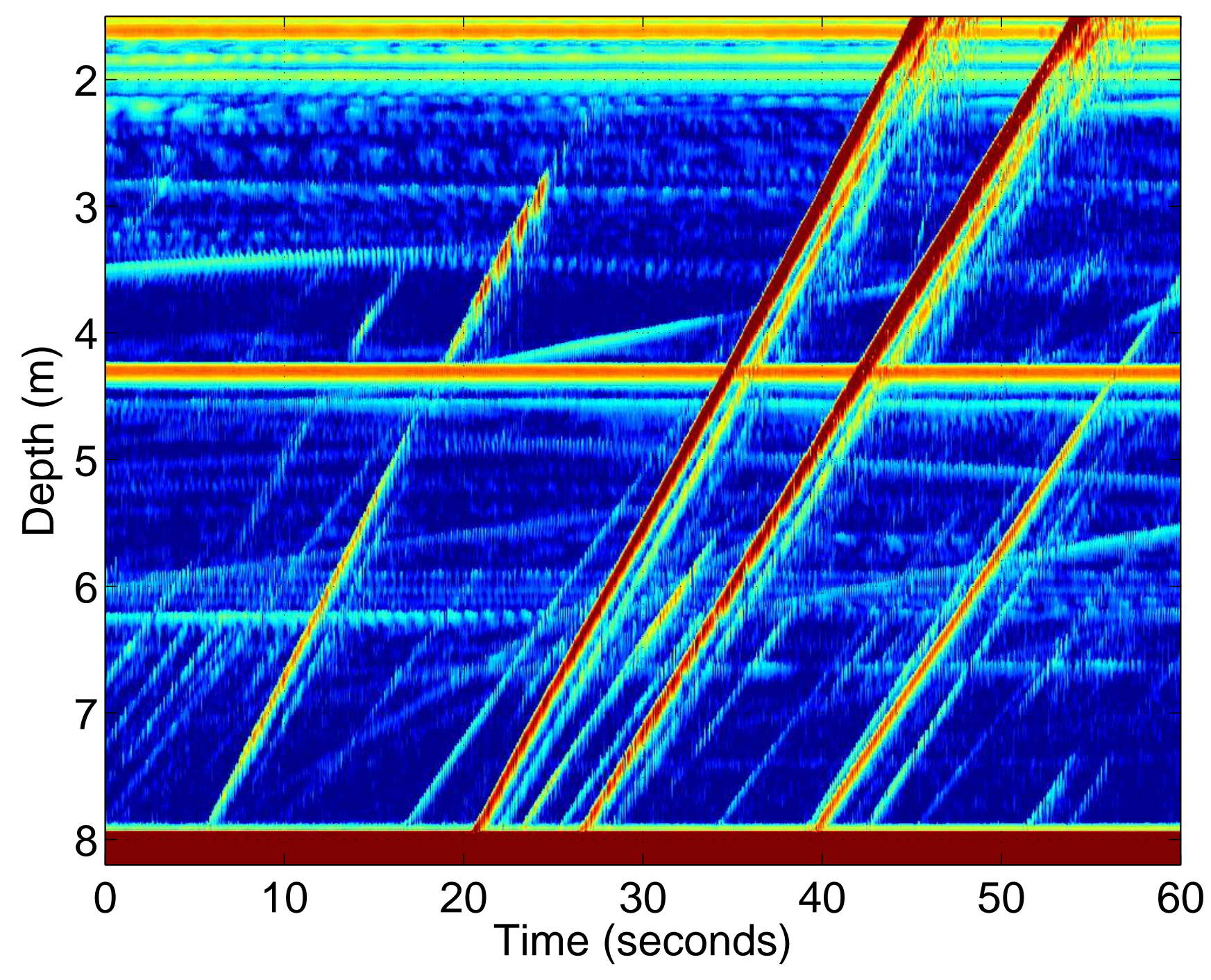



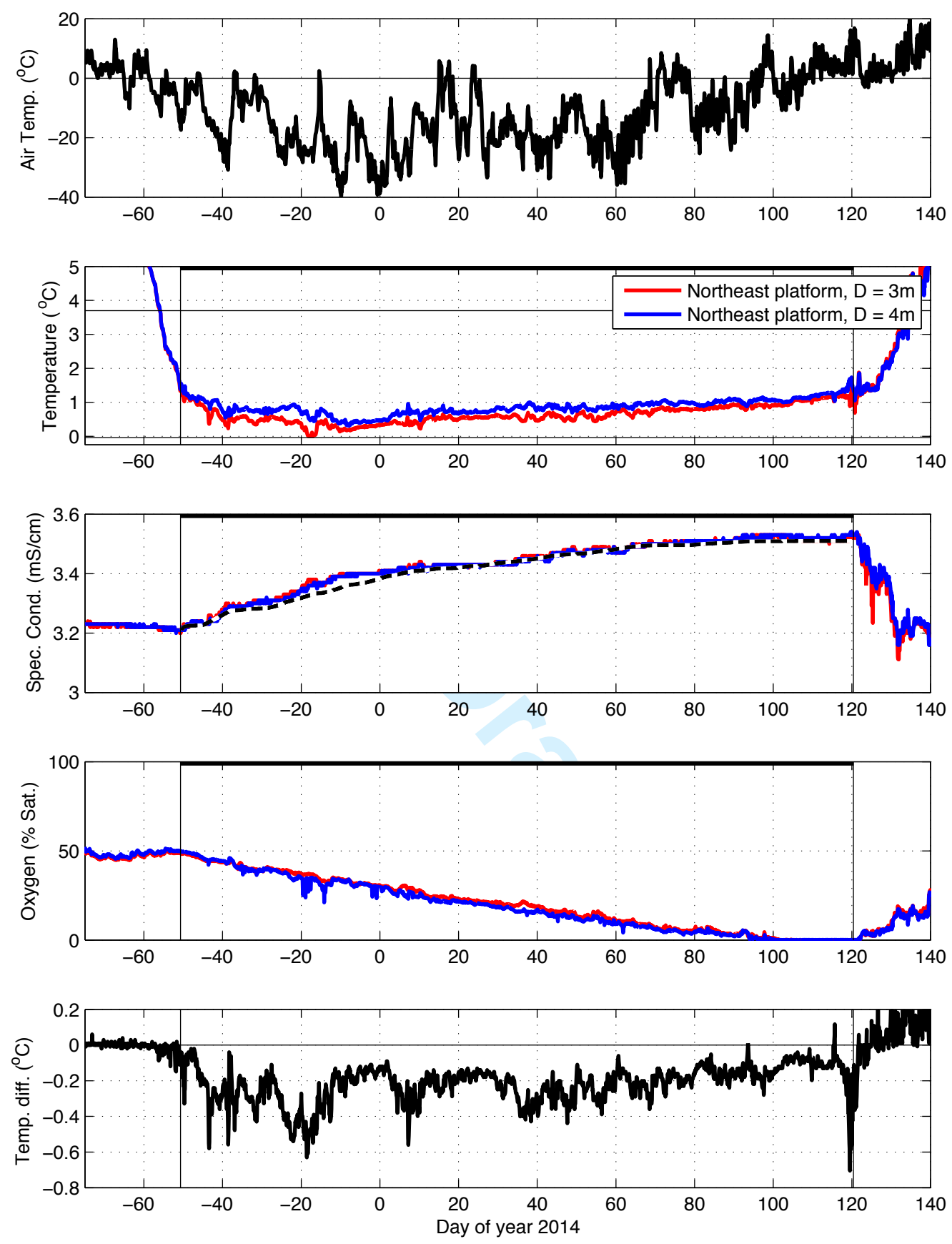

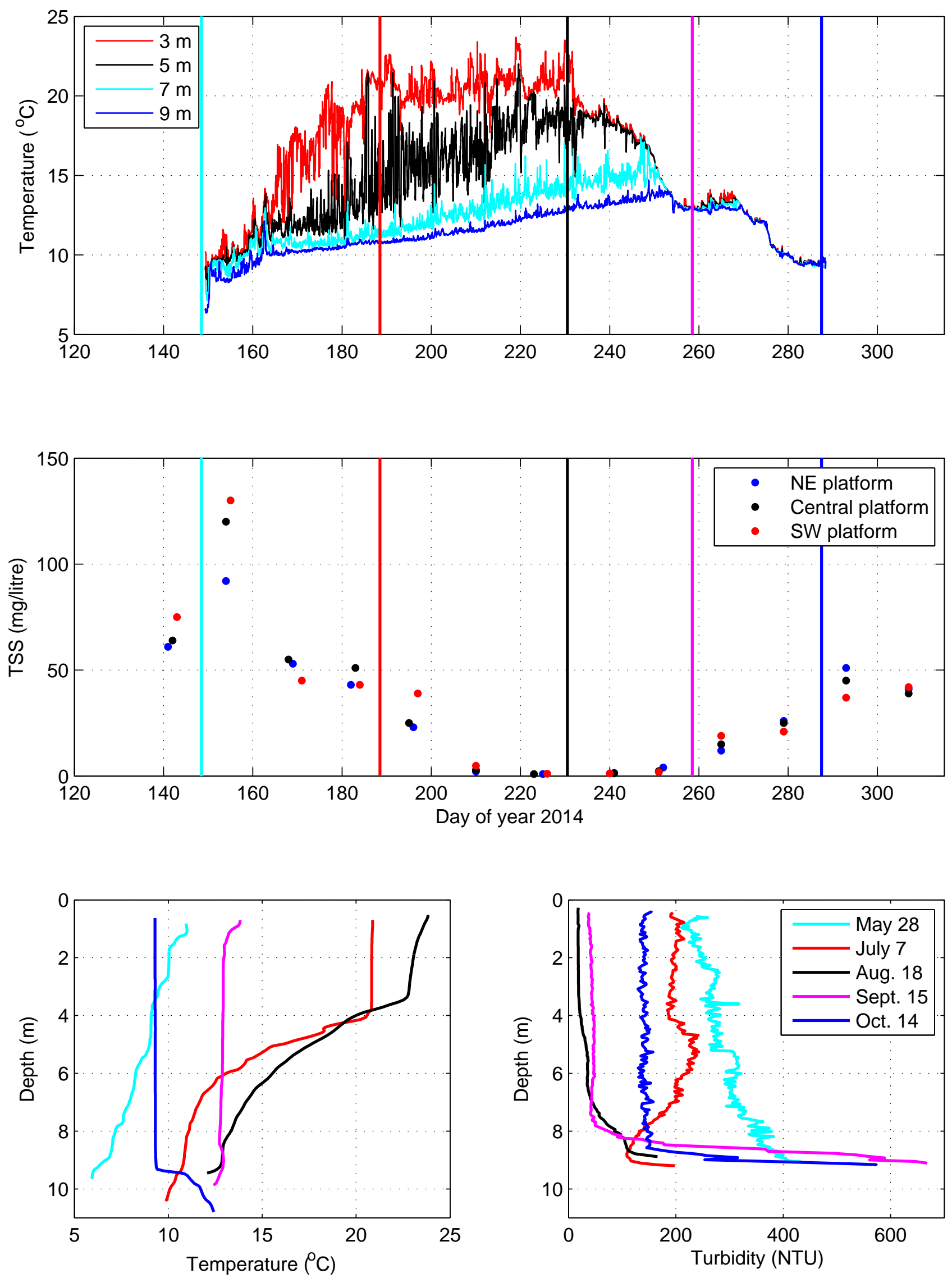